\title{
Lower-speed electric drills create less aerosol spray
}

Dentists could significantly increase the number of patients they see during the pandemic by switching the drills they use, according to new research led by the University of Leeds. ${ }^{1}$

The study investigated whether different drill types increased or reduced the spread of aerosol spray in a dental surgery. Reducing aerosol spray results in a safer environment for patients and the dental team.

The findings show that the time taken to prepare safe surgeries between appointments could be radically reduced by changing drills, potentially resulting in millions more treatments being carried out.

The study compared the aerosol patterns produced by dental drills rotated by air streams - that are most commonly used by UK dentists - to those produced by electric-powered drills.

Instead of simply mapping the spread of water spray during treatment, the research team instead introduced a virus that is similar in size and structure to the SARS-CoV-2 virus that causes COVID-19.

Their results show that by replacing the high-speed air drills with lower-speed electric drills, aerosol spray was virtually eliminated, creating a safer environment for both patients and the dental team.

Lead clinical author Professor Brian Nattress said: 'The issue for dentists during the coronavirus pandemic is that their routine work involves creating an aerosol spray in a confined space with an associated risk of airborne spread of COVID-19. This is the first time the spread of a harmless COVID-19-like virus has been analysed during routine drilling procedures.

'If the spread of that aerosol spray can be reduced or eradicated, that has enormous, positive implications for how dentists can go about their daily business not just during the coronavirus pandemic, but also during future virus outbreaks.'

During the new research tests, use of the electric drill rather than an air drill led to a $99.98 \%$ reduction in aerosol spread of the virus into the air. When a dental suction tool was added, there was no detectable virus on surfaces or in air samples taken six to ten minutes afterwards.

The research team set up simulated dental treatments in a real surgery scenario and - for the first time ever - used a harmless virus to track the spread of aerosols in the air and on surfaces.

A dummy head and simulated saliva were used to measure the difference between the level of aerosols generated using a conventional air-driven dentist's drill and a more modern electric handpiece.

In light of the many restraints placed on dentists globally since the beginning of the pandemic, the research team is calling for further and essential studies to find different strategies to control the spread of dental aerosols and help to reduce the current backlog of patients.

\section{Reference}

1. Vernon J J, Black E V I, Dennis T et al. Dental mitigation strategies to reduce aerosolization of SARS-CoV-2. J Dent Res 2021; doi: 10.1177/00220345211032885.

\section{Lost decade on pay undermining NHS dentistry's COVID recovery}

The British Dental Association (BDA) says a historic collapse in dentists' earnings across the UK is jeopardising the long-term recovery of the service from the COVID-19 pandemic.

BDA analysis of new official figures on earnings and expense levels in NHS dental practice ${ }^{1}$ (published on 19 August) shows high-street dentists in England have seen taxable income fall by nearly $40 \%$ in real terms over the last decade. The story is replicated across the UK nations, with real terms falls in Wales, Scotland and Northern Ireland of well over a third since 2009.

The new 2019/20 figures capture the period just before the first lockdown. Above-inflation uplifts have remained the exception rather than the rule since the financial crash, with across-the-board cuts in pay in both cash and real terms.

Unlike their medical colleagues, NHS dentists do not typically receive any capital investment from central government, with profits funding all improvements in equipment, training and facilities for NHS practices. While devolved governments have provided millions to invest in new ventilation systems, to help increase patient numbers while maintaining strict infection prevention and control measures, there have been no parallel commitments from Westminster. Practices are also facing mounting costs for clinical waste and essential equipment, without comprehensive support.

The BDA has warned continued pay restraint will only accelerate the drift away from NHS dentistry. Recent surveys have shown that nearly half (47\%) of dentists in England indicate they are now likely to change career or seek early retirement in the next 12 months should current COVID restrictions remain in place. The same proportion state they are likely to reduce their NHS commitment.

The historic driver of low morale in the sector remains the discredited target-based NHS dental contract imposed on the profession in 2006, which has proved incompatible with providing care during the pandemic.

Prior to COVID, unmet need for NHS dental services was already estimated at over 4 million, or one in ten of the adult population. Over 30 million NHS appointments have been lost since the first lockdown in England alone.

Shawn Charlwood, the BDA's Chair of the BDA's General Dental Practice Committee, said: 'Government has taken the "do more with less" mantra to the nth degree. Every penny of investment in this service comes from dentists' own pockets. This historic squeeze has left practices unable to deliver needed improvements in facilities, equipment and training, even before the added costs of COVID arrived.

'The pandemic has exposed the rotten foundations this service is built on, with failed systems and underinvestment leaving millions unable to secure the care they need.

'Dentists need to see this service as a place they'd choose to build a career. From discredited contracts to flatlining pay, no one should be penalised for working in the NHS.

\section{Reference}

1. NHS Digital. Dental Earnings and Expenses Estimates 2019/20. 19 August 2021. Available at: https://digital.nhs.uk/data-and-information/publications/statistical/ dental-earnings-and-expenses-estimates/2019-20 (accessed August 2021). 